\title{
UWB Antenna Optimization Using Linear Regression for Wireless Capsule Endoscopy Application in WBAN
}

\author{
Mutiara Kaffa ${ }^{1}$, Miftadi Sudjai ${ }^{2}$, Bambang Setia Nugroho ${ }^{3}$ \\ \{kaffamutiara@student,miftadi@,bambangsetianugroho@\} \\ telkomuniversity.ac.id \\ Telkom University, Bandung, Indonesia
}

\begin{abstract}
Wireless Capsule Endoscopy (WCE) is a wireless technique of endoscopic exploration which offers to depict whole gastrointestinal (GI) tract including small intestine which is hard to explore using conventional endoscopy. Transmitting high image resolution data with low power consumption is main challenge of WCE, where the antenna plays major role in WCE system. In this research, we proposed a technique to optimize the Ultra Wide Band (UWB) antenna working in the frequency band between $3.1 \mathrm{GHz}$ to 10.6 GHz. The antenna performs well inside human body in terms of bandwidth, gain, size, and radiation pattern. In order to improve antenna's performance, we propose an antenna optimization by using a linear regression. The optimization is based on analyzis using predesigned antenna from previous research, that is a UWB slotted microstrip antenna with half ground plane with size of $10 \times 8 \mathrm{~mm}$. The validation of this optimization technique is done by using a simulation. This UWB Capsule Endoscopy antenna performance is assesed in terms of return loss, antenna gain and radiation pattern which has lower than $-10 \mathrm{~dB}$, higher than $-9 \mathrm{~dB}$, and omnidirectional radiation pattern, respectively.
\end{abstract}

Keywords: Antenna Formula, Wireless Body Area Network (WBAN), Ultra Wideband (UWB), Capsule Endoscopy.

\section{Introduction}

The best way to diagnose and detect gastrointestinal (GI) tract diseases is by directly view and explore the GI tract itself. There are many methods to explore the GI tract such as conventional endoscopic, colonoscopy and wireless endoscopy. Conventional endoscopy and colonoscopy is an invasive way to explore th GI tract while Wireless Capsule Endoscopy (WCE) is a non-invasive way [1], [2]. WCE is a wireless technique of endoscopic exploration which offers to depict whole GI tract. WCE consist of a wireless chip camera which captures the condition of GI tract, a lens, an LED, a radio transmitter and battery module to power up the whole system. Patient will swallow the capsule which mostly has size of 11 x $22 \mathrm{~mm}$ [3]. The WCE will explore the GI tract by the help of peristaltic movement inside the body and will be excreted naturally[4].

Providing high image resolution with low power consumption and high data rate transmission is main challenge in WCE system. It is stated that WCE system is one of WBAN application which need high data rate to give a real time and up-to-date exploration and high image resolution that will resulted more accurate diagnosis [5][6]. Antenna plays major role in WCE system. An UWB antenna is a good choice to overcome the challenges. Federal 
Communication Comission (FCC) defined UWB has bandwidth of at least $500 \mathrm{MHz}$ and operate in the $3.1-10.6 \mathrm{GHz}$ band and the transmitted power density limited to less than -41.3 $\mathrm{dBm} / \mathrm{MHz}$ [5][6][7]. IR-UWB communication has been choosen by IEEE 802.15.6 task group as a possible physical layer solution for WBAN. On previous research, an UWB antenna is proposed with size of $12 \mathrm{~mm} \times 8 \mathrm{~mm} \times 1.94 \mathrm{~mm}$ and gain value between $-11.87 \mathrm{~dB}$ to -6.584 $\mathrm{dB}$ [8]. This antenna occupy 6 IR-UWB channels with the $-10 \mathrm{~dB}$ bandwith of antenna approximately $3 \mathrm{GHz}[8]$.

The main objective of this paper is to get a technique or formula to make the most optimized antenna which works well with WCE system inside human body with working frequency between $3.1 \mathrm{GHz}$ to $10.6 \mathrm{GHz}$. In order to get the most optimized antenna, a formula for optimization is proposed using linear regression. The formula is analyzed using the antenna design from previous research. The formula obtained from the research will be validated using a simulation software and presented in math model.The WCE devices later will be working inside human body and will have direct contact with it. To find the formula to get the most optimize antenna, human tissues electrical properties should be taken into account because human body tissues are highly frequency dependent.

This paper is organized as follows: Section 2 Antenna Design and scenario. Section 3 presents Results and Analysis and finally Section 4 will concludes the paper.

\section{Antenna Design and Scenario \\ 2.1 Antenna and Phantom Design}

The proposed math model (formula) from linear regression and antenna will be analyze and simulated in a analysis tools and simulation software. The formula obtained from this research will be validated using simulation software and later the antenna design will be validate using pig's abdominal part as substitute of human body (phantom).
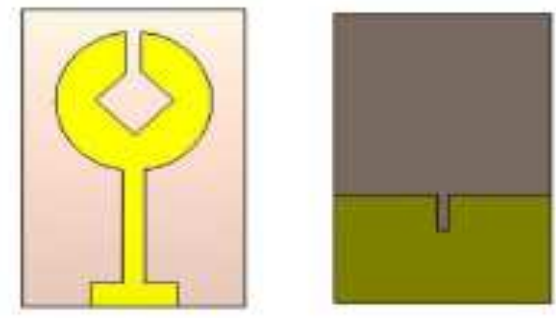

Figure 1. Front view of UWB antenna (left) and back view (right) [8]

The antenna design that will be use as standard antenna to obtain a formula in this paper is a UWB antenna from previous research shown in figure 1 [8]. The planar antenna is choosen since it can gives omnidirectional radiation pattern with low profile shape rather than monopole antenna [9][10]. The size of the antenna is also a challange in WCE system, it should be fitted into the capsule considering WCE's capsule has to be swallow by the patient [11][12]. Mostly the size of the capsule is $11 \times 22 \mathrm{~mm}$. High frequency material, Roger 6010 will be use with dielectric constant of $\varepsilon r 10.2$ and thickness of $1.9 \mathrm{~mm}$ antenna. It is choosen because its low loss 
and it has high dielectric constant to minimize the antenna size. This substrate also has low moisture absorption that will reduce the effect of moisture in electrical loss. Figure 2 and Tabel 1 shows the antenna dimension that will be use in this research. 

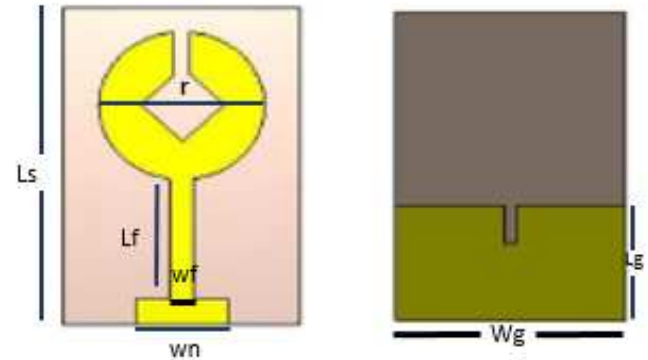

Figure 2. Antenna Design and Parameters

Table. 1 Antenna Dimension

\begin{tabular}{lc}
\hline \multicolumn{1}{c}{ Parameters } & Value (mm) \\
\hline Length of ground (Lg) & 4.5 \\
Width of ground an substrate (Wg) & 8 \\
Thickness of ground and patch (hg) & 0.035 \\
Thickness of substrate (hs) & 1.9 \\
Width of ground notch (Wn) & 0.4 \\
Length of ground notch (Lgs) & 1.5 \\
Length of substrate (Ls) & 12 \\
Width of rectangular slit in patch (ws) & 0.6 \\
Length and wide of square slot in patch (sq) & 3 \\
Width of feed line (wf) & 0.8 \\
\hline
\end{tabular}

As mentioned before, human tissues electrical properties should be taken into account because human body tissues are highly frequency dependent. To validate that the formula and the antenna works well inside human body, then the simulation should be done using a gastrointestinal phantom shown in figure 3 . In this paper, the simulation only use small intestine phantom as shown in figure 4.

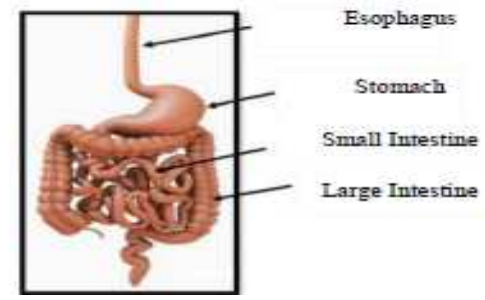

Figure 3. Human Gastrointestinal Tract [4] 


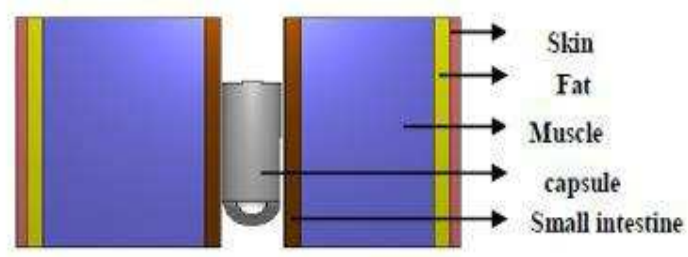

Figure 4. Small Intestine Phantom

Phantom is a modeling of the human body used in antenna simulation. Phantom has permittivity characteristics $(\varepsilon)$, permeability $(\mu)$ and conductivity value according to body part where antenna is placed. Phantom is very important in the design of wireless body area netwok because the human body has a very significant influence on the characteristics of the antenna to be designed. Table 2 below shows that each tissues in human body has different electrical properties value.

Table. 2 Tissues Electrical Properties in $9.31 \mathrm{GHz}$ [13]

\begin{tabular}{cccc}
\hline Tissue & Dielectric Constant & $\begin{array}{c}\text { Conductivity } \\
{[\mathrm{S} / \mathrm{m}]}\end{array}$ & $\begin{array}{c}\text { Loss } \\
\text { tangent }\end{array}$ \\
\hline Skin (Dry) & 31.955 & 7.2373 & 0.43729 \\
Fat & 4.6558 & 0.5359 & 0.22224 \\
Muscle & 43.702 & 9.6333 & 0.4256 \\
Small Intestine & 43.087 & 11.665 & 0.52272 \\
\hline
\end{tabular}

Phantom used in the simulation is a composition of the human body tissue of the abdomen that is, skin, fat, muscle and small intestine with the value of permittivity, conductivity and different thickness.

\subsection{Scenario}


To improve the aforementioned UWB antenna which works well inside human body in the frequency between $3.1 \mathrm{GHz}$ to $10.6 \mathrm{GHz}$, an optimization formula is needed.The analysis starts from choosing the basic antenna design, later, with the choosen antenna design, each of the variable in the antenna will be change one by one to build pairs of possibilities. There are two kind of variables, dependent and independent variables. The independent variable is the changing variable while the dependent variable are gain and bandwidth.

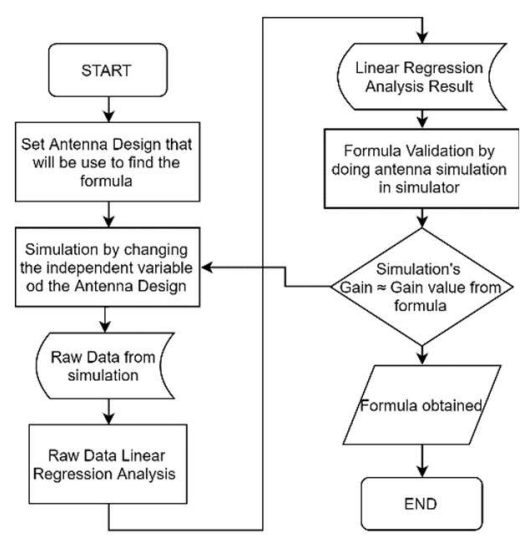

Figure 5. Flow chart scenario

Figure 5 explains the flow chart of this reasearch. First step, the antenna from previous works [14] will be simulated in simulator shown in figure 6 to obtain raw data. The parameter of the antenna which are length and width of feed, groundplane, radius will be changed one by one. The changing variable above called independent variable in linear regression. Once the data has been collected, the data will be analyze using linear regression to see if the characteristic of datas is linear or not. There will be error value in the data analysis, if the error value is less tatn $1 \%$ then the simulation will be performed again to ensure that the math model obtained from the raw data analysis is valid or not.
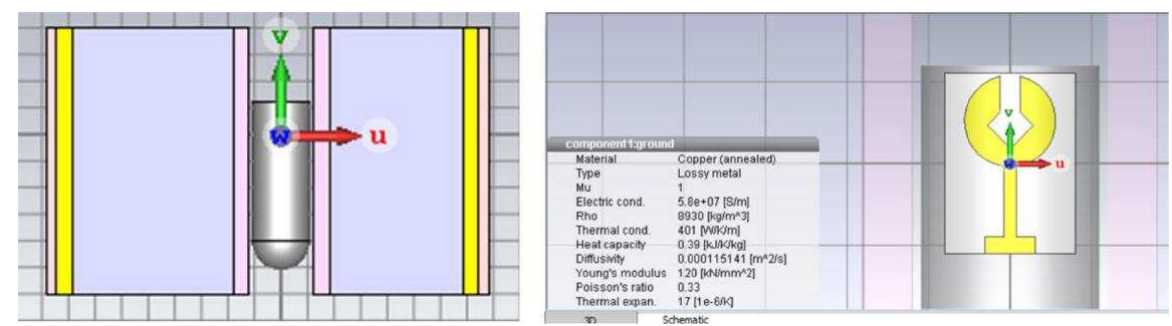

Figure 6. Validation Simulation

After simulation performed, we will check whether the value from math model obtained and the simulation result obtain is the same or not. If the differences between the math model 
value and simulation value is small, then the math model is confirmed as a valid formula to obtain the most optimized antenna.

\section{Result and Analysis}

Table. 3 Raw Data from Simulation

\begin{tabular}{cccccc}
\hline No & $\begin{array}{c}\text { Gain } \\
\text { (numeric) }\end{array}$ & $\begin{array}{c}\text { Frequency } \\
(\mathrm{GHz})\end{array}$ & $\begin{array}{c}\text { Return Loss } \\
\text { (numeric) }\end{array}$ & $\begin{array}{c}\text { Length of feed } \\
\text { line }(\mathrm{mm})\end{array}$ & $\begin{array}{c}\text { Radius of } \\
\text { patch (mm) }\end{array}$ \\
\hline 1 & 0.058884 & 6.85 & 0.042228 & 5.3 & 2.8 \\
2 & 0.113763 & 8.35 & 0.033052 & 5.3 & 2.8 \\
3 & 0.058884 & 6.85 & 0.043202 & 5.4 & 2.8 \\
4 & 0.11246 & 8.35 & 0.035596 & 5.4 & 2.8 \\
5 & 0.060256 & 6.85 & 0.044937 & 5.1 & 2.8 \\
6 & 0.116145 & 8.35 & 0.034898 & 5.1 & 2.8 \\
7 & 0.057544 & 6.85 & 0.048273 & 5.3 & 2.7 \\
8 & 0.11324 & 8.35 & 0.045279 & 5.3 & 2.7 \\
9 & 0.058884 & 6.85 & 0.032337 & 5.3 & 2.9 \\
10 & 0.110154 & 8.35 & 0.031246 & 5.3 & 2.9 \\
\hline & & & & &
\end{tabular}

Table 3 show the result of antenna simulation with changing variable (independent variable) that will be use as raw data to be tested in linear regression analysis and antenna simulation validation. The raw data consist of independent variable, gain value, working frequency and return loss. The raw data above will be analyze using anlysis tools to calculate if the data gain from the simulation is valid and have low error value or not. The analysis will use linear regression method which resulted like this :

Table. 4. Regression Statistic from Raw Data

\begin{tabular}{lr}
\hline \multicolumn{2}{c}{ Regression Statistics } \\
\hline R Square & 0.999158 \\
Adjusted R Square & 0.998485 \\
Standard Error & 0.001115 \\
Observation & 50 \\
\hline
\end{tabular}


From table 4 it shows that the raw data presented in table 3.5 has 0.001114928 or $0.1 \%$ standard error. So, the raw data is good enough to be analyze and the formula that shown later is good enough because it has small standard error.

Table 5. Result of raw data analysis

\begin{tabular}{crr}
\hline & Coefficients & \multicolumn{1}{c}{ Standard Error } \\
\hline Intercept & -0.102475312 & 0.033321547 \\
$\mathrm{f}$ & 0.035788706 & 0.00058149 \\
$\mathrm{RL}$ & -0.093635665 & 0.083061933 \\
If & -0.00961199 & 0.003676385 \\
$\mathrm{r}$ & -0.010183271 & 0.003633275 \\
\hline
\end{tabular}

Table 5 shows the formula that will be validate using simulator software. This table resulting a formula from length of feed and patch radius variable pairs only.

$$
\begin{aligned}
\text { Gain } \cong & (0.0357887061264201 \times \text { f })+(-0.00961199 \times \text { lf })+(-0.010183271 \times \text { r })+ \\
& (-0.102475312)
\end{aligned}
$$

With above math model, a simulation is performed to ensure that the formula is valid or not. The simulation will change the length of antenna feed from 5.4, 5.3, 5.2 and 5.1 with $0.1 \mathrm{~mm}$ steps in each simulation and no changes in other parameter. While in the second simulation the simulation will change the radius of patch with $0.1 \mathrm{~mm}$ steps start from $2.9 \mathrm{~mm}$ to $2.7 \mathrm{~mm}$. 
Table 6. Gain Value from math model and simulation

\begin{tabular}{ccccccc}
\hline $\mathbf{N o}$ & $\begin{array}{c}\mathbf{F} \\
(\mathbf{G H z})\end{array}$ & If $(\mathbf{m m})$ & $\begin{array}{c}\mathbf{r} \\
(\mathbf{m m})\end{array}$ & $\begin{array}{c}\text { Gain from } \\
\text { formula }(\mathbf{d B})\end{array}$ & $\begin{array}{c}\text { Gain from } \\
\text { simulation (dB) }\end{array}$ & Deviation \\
\hline 1 & 6.85 & 5.3 & 2.8 & -12.27 & -12.3 & 0.03 \\
2 & 8.35 & 5.3 & 2.8 & -9.44 & -9.44 & 0.00 \\
3 & 6.85 & 5.4 & 2.8 & -12.35 & -12.3 & 0.05 \\
4 & 8.35 & 5.4 & 2.8 & -9.48 & -9.49 & 0.01 \\
5 & 6.85 & 5.1 & 2.8 & -12.15 & -12.2 & 0.05 \\
6 & 8.35 & 5.1 & 2.8 & -9.37 & -9.35 & 0.02 \\
7 & 6.85 & 5.3 & 2.7 & -12.24 & -12.4 & 0.16 \\
8 & 8.35 & 5.3 & 2.7 & -9.44 & -9.46 & 0.02 \\
9 & 6.85 & 5.3 & 2.9 & -12.28 & -12.3 & 0.02 \\
10 & 8.35 & 5.3 & 2.9 & -9.47 & -9.58 & 0.11 \\
& & & & & & $\mathbf{0 . 0 5}$ \\
\hline
\end{tabular}

Table 6 above shows Gain obtained from formula (1) and Gain obtained from simulation. It shows that both techinque has slightly difference value of Gain. The average deviation between this technique is 0.05 . Antenna gain value must be suitable for WCE system because later the antenna will operate inside human body which has different temperature and conditions [15].
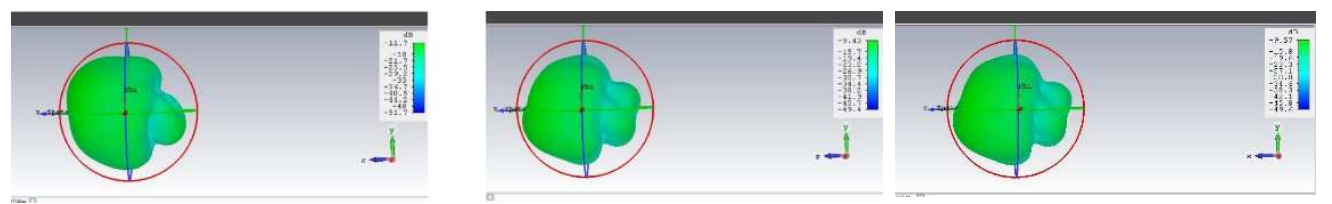

Figure 7. Radiation pattern in lowest, middle and highest working frequency

\section{Conclusion}

The formula obtain from this research is valid enough because it has low error value and low deviation but further reserach is needed to ensure that the math model is valid to obtain better antenna. More datas from previous research will be analyze and more independent variables will be added to make the math model more accurate. The frequency that will be use as dependent variable also should be develop in to 3 working frequency which are lowest working frequency, middle and highest working frequency. The formula obtained also has to be checked in other range of frequency as long as the antenna still placed inside the body.

\section{Acknowledgements.}

The succesful completion of this paper would be incomplete without mentioning the names of those parties who helped to make it possible. We take this opportunity to express our gratitude to Telkom University for the valuable support both financial support and technical support. 


\section{References}

[1] M. Zhou, Z. Feng, X. Huang, Youjian, and Liu, "Maximum A Posteriori Probability (MAP) Joint Fine Frequency Offset and Channel Estimation for MIMO Systems with Channels of Arbitrary Correlation," May 2019.

[2] S. N. Adler and Y. C. Metzger, "PillCam COLON capsule endoscopy: recent advances and new insights.," Therap. Adv. Gastroenterol., vol. 4, no. 4, pp. 265-8, Jul. 2011, doi: 10.1177/1756283X11401645.

[3] “Amazon.com: endoscopy." [Online]. Available: https://www.amazon.com/s?k=endoscopy\&adgrpid=82339058380\&gclid=Cj0KCQiA jfvwBRCkARIsAIqSWIMKaRV_nWQe1zyp5pEjRKnUI02dzpB3Q3zBjyOQgpA2cd 281ozqEH8aAqwtEALw_wcB\&hvadid $=393489168622 \&$ hvdev $=$ c\&hvlocphy $=907256$ 9\&hvnetw $=\mathrm{g} \&$ hvpos $=1 \mathrm{t} 1$ \&hvqmt $=\mathrm{b} \&$ hvrand $=17309689982675818754 \&$ hvtargid $=\mathrm{kw}$ d-14146180\&hydadcr $=17515$ 11240655\&tag=hydglogoo20\&ref=pd_sl_2j310hedep_b. [Accessed: 15-Jan-2020].

[4] "Inclusive Society: Health and Wellbeing in the Community, and Care at Home ... Google Buku." [Online]. Available: https://books.google.co.id/books?id=FLG7BQAAQBAJ\&pg=PA174\&lpg=PA174\&d $\mathrm{q}=\mathrm{A} .+$ Moglia,,+ A. + Menciassi, + M. + Schurr,$+\mathrm{P} .+$ Dario,,$+\% 22$ Wireless + capsule + endosc opy:+from+diagnostic + devices + to + multipurpose + robotic + systems $\% 22,+$ Biomedical + microdevices, + vol. $+9,+$ no. $+2,+$ pp. $+235-$

$243,+$ April $+2007 . \&$ source $=$ bl\&ots $=$ 754B6CBYy\&sig $=$ ACfU3U2yhdVk7udaGx $5 \mathrm{ktls}$ sfeyAQWnxWQ\&hl=id\&sa=X\&ved=2ahUKEwi2lPnOnYXnAhXTTX0KHSjaAzsQ6 AEwAHoECAkQAQ\#v=onepage\&q=A. Moglia\%2C A. Menciassi\%2C M.

Schurr\%2C P. Dario\%2C \%22Wireless capsule endoscopy\%3A from diagnostic devices to multipurpose robotic systems $\% 22 \% 2 \mathrm{C}$ Biomedical microdevices $\% 2 \mathrm{C}$ vol. 9\%2C no. 2\%2C pp. 235-243\%2C April 2007.\&f=false. [Accessed: 15-Jan-2020].

[5] "VLSI Circuits for Biomedical Applications - Krzysztof Iniewski - Google Buku." [Online]. Available: https://books.google.co.id/books?id=-

W5bBvq70_0C\&pg=PA142\&lpg=PA142\&dq=\%5D+FCC+Rules+and+Regulations, + $\% 22$ MICS+Band+Plan, $\% 22+$ p. + Part $+95,+$ Jan $+2003 . \&$ source=bl\&ots=Ocp6QcjnHy \& sig=ACfU3U2k9Aik2CqCy9_E0MGrlTsbeXBlcg\&hl=id\&sa=X\&ved=2ahUKEwiQw pzWnYXnAhVKWH0KHT2dDSEQ6AEwAHoECAcQAQ\#v=onepage\&q=\%5D FCC Rules and Regulations\%2C \%22MICS Band Plan\%2C\%22 p. Part 95\%2C Jan 2003.\&f=false. [Accessed: 15-Jan-2020].

[6] “iRIScope Software | Mobile Aspects.” [Online]. Available: https://www.mobileaspects.com/solutions/iriscope/?gclid=Cj0KCQiAjfvwBRCkARIs AIqSWlOGtaoJ9EKp2Ra8UnH6FtmPGYEmirye4_b7YRL0v0hyywjfEHEAtuoaAsIX EALw_wcB. [Accessed: 15-Jan-2020].

[7] "FCC \& ISED Canada Testing at D.L.S. - D.L.S. Electronic Systems, Inc." [Online]. Available: http://www.dlsemc.com/fcc-ised-canada-testing-at-d-l-s/?gwds-fcc. [Accessed: 15-Jan-2020].

[8] "Developer-Manufacturer Of Wearable Antenna Products." [Online]. Available: https://www.octanewireless.com/products/wearable-antennas/. [Accessed: 15-Jan2020]. 
[9] H. Schantz, The art and science of ultrawideband antennas. .

[10] “Antenna Manufacturing With E-FAB Photo Etching Techniques | Photo Etching, Photo Chemical Machining \& Micro Milling." [Online]. Available: https:/efab.com/products/etchedantennas/?gclid=Cj0KCQiAjfvwBRCkARIsAIqSWINXiGt9SIeeYBogtpKR_NWzGU CahYT8M9nAaszYr7hc8xU4F64WgUMaAseXEALw_wcB. [Accessed: 15-Jan2020].

[11] W. El-Matary, "Wireless Capsule Endoscopy: Indications, Limitations, and Future Challenges," J. Pediatr. Gastroenterol. Nutr., vol. 46, no. 1, pp. 4-12, Jan. 2008, doi: 10.1097/01.mpg.0000304447.69305.cc.

[12] Y. Gu et al., "Design of Endoscopic Capsule With Multiple Cameras," IEEE Trans. Biomed. Circuits Syst., vol. 9, no. 4, pp. 590-602, Aug. 2015, doi: 10.1109/TBCAS.2014.2359012.

[13] "Dielectric Properties of Body Tissues: HTML clients." [Online]. Available: http://niremf.ifac.cnr.it/tissprop/htmlclie/htmlclie.php. [Accessed: 15-Jan-2020].

[14] "Harxon Corporation." [Online]. Available: https://en.harxon.com/products.php?CateId=13\&gclid=Cj0KCQiAjfvwBRCkARIsAIq SWlOwMFfyHbj14h-ucgPBTiekqhfRlo-P-

NvmzgndKVNeMU6YJzyevhsaAnmfEALw_wcB. [Accessed: 15-Jan-2020].

[15] K. M. S. Thotahewa, J.-M. Redoute, and M. R. Yuce, "Propagation, Power Absorption, and Temperature Analysis of UWB Wireless Capsule Endoscopy Devices Operating in the Human Body," IEEE Trans. Microw. Theory Tech., vol. 63, no. 11, pp. 3823-3833, Nov. 2015, doi: 10.1109/TMTT.2015.2482492. 